\title{
Lifelong Learning in a Learning Society: Are Community Learning Centres the Vehicle?
}

\author{
Manzoor Ahmed
}

\begin{abstract}
This chapter provides a historical perspective on the evolving concepts of lifelong learning and the learning society and makes the case for the community learning centre as a potential institutional vehicle for the promotion of adult and lifelong learning. It highlights the pertinence of lifelong learning/learning society in the post-2015 Development Agenda discourse. Arguments in favour of the community learning centre as a vehicle for lifelong learning/learning society are illustrated using the example of Bangladesh and drawing on parallels and contrasts with China and India. Finally, lessons derived from a recent review of the Asia-Pacific region are evaluated with respect to the development of strategic actions intended to offer adult and lifelong learning within and through community learning centres.
\end{abstract}

[O]nly an over-all, lifelong education can produce the kind of complete man the need for whom is increasing with the continually more stringent constraints tearing the individual asunder. We should no longer assiduously acquire knowledge once and for all, but learn how to build up a continually evolving body of knowledge all through life-'learn to be.'

'Lifelong education' and 'the learning society' were the key takeaways of the 1972 report of the Faure Commission. The former was seen as the keystone

1 Excerpt from letter of Edgar Faure, Chairman of the International Commission on the Development of Education, to René Maheu, Director-General of United Nations Educational, Scientific and Cultural Organization (UNESCO), in regard to the presentation of the report of the Commission, Learning to Be: The World of Education Today and Tomorrow, 18 May 1972, vi.

(C) Graduate Institute of International and Development Studies, 2014 ～DOI 10.1163/9789004281158_007 This is an open access chapter distributed under the terms of the Creative Commons Attribution- 
of education policy, the latter a strategy to involve society as a whole as a participant and actor in education (Faure et al., 1972). How have the two related ideas, innate in learning as a social function, evolved with the institutionalisation of education? Have they gained new relevance in the globalised world of knowledge economies and information societies? Do they call for creating or re-inventing an institutional mechanism distinct from, yet complementary to, traditional formal educational institutions? This chapter explores these questions. As stated by the Faure report, 'If learning involves all of one's life, in the sense of both time-span and diversity, and all of society, including its social and economic as well as its educational resources, then we must go even further than the necessary overhaul of 'educational systems' until we reach the stage of a learning society' (Faure et al., 1972, xxxiii).

In the 1970s, at about the time of the Faure Commission report, the three-fold typology of education - formal, non-formal and informal-gained currency. Recognising that 'education is obviously a continuing process, spanning the years from earliest infancy through adulthood and necessarily involving a great variety of methods and sources', Coombs and Ahmed distinguished between the three modes of education as 'analytically useful, and generally in accord with current realities'. They went on to argue that 'the need now is to visualise the various educational activities as potential components of a coherent and flexible overall learning system that must be steadily strengthened, diversified and linked more closely to the needs and processes of national development'. They underscored the emerging consensus that nations should strive to build 'lifelong learning systems', offering every individual diverse learning opportunities throughout her or his lifetime (Coombs and Ahmed, 1974, 9).

This theme was picked up again, two decades later, by the United Nations Educational, Scientific and Cultural Organization (UNESCO) International Commission on Education for the Twenty-first Century in its report Learning The Treasure Within:

The concept of learning throughout life is the key that gives access to the twenty-first century. It goes beyond the traditional distinction between initial and continuing education. It links up with another concept often put forward, that of the learning society, in which everything affords an opportunity of learning and fulfilling one's potential [...]. In short, 'learning throughout life' must take advantage of all the opportunities offered by society. (Delors et al., 1996, 38)

The Belem Framework for Action, announced at the 6th International Conference on Adult Education (CONFINTEA VI), affirmed that lifelong 
learning 'from cradle to grave' is a philosophy, a conceptual framework and an organising principle of all forms of education, based on inclusive, emancipatory, humanistic and democratic values' (UIL, 2009, 1). Lifelong learning is as old as humanity itself. As observed by Ye, lifelong learning was there before education was invented' (Ye cited in UIL, 2010, 6). It was only as social functions became increasingly specialised and institutionalised that the idea of lifelong learning was eclipsed by the ascendancy of formal education in childhood and early adulthood (Ye cited in UIL, 2010). Today, the idea highlighted in the 1970s by the Faure Commission, among others, has gained new relevance in the context of a learning society where the acquisition and use of knowledge and information have taken on still greater importance, giving rise to the evocative terms 'knowledge economy' and 'information society.'

The notion of the learning society underscores learning as an activity, rather than something tied to a specific place or an institutional setting. It emphasises the social context, purpose and character of learning and its existence both inside and outside educational institutions. More importantly, the concept of the learning society highlights the exigency of learning occurring not only within, but also out of, and around, formal institutional settings (Cisco Systems, 2010). In his book, The Learning Society, Robert Hutchins framed the learning society as a response to the ever-changing nature of the modern state and society and the correspondingly inability of institutional education to keep pace. Torsten Husén, in revisiting the concept, highlighted the need for a 'fluidity' of learning, in line with the free movement of knowledge required by the organisations and systems of global society (Hutchins, 1970; Husén, 1986).

\subsection{The Premises of the Learning Society}

Cisco Systems, a multinational information technology corporation, amongst others, saw the links between information and communication technology, the potential change in the nature and modalities of learning, and explored the notion of the learning society. It argues that the principles that characterise the learning society 'are informed by the demands of the 21st century, by emergent innovations at the very leading edge, and by what we now know about how learning happens' (Cisco Systems, 2010, iv). The company proposes the following set of principles to help meet society's new demands for learning and realise the learning potential of both societies and individuals. 
The learning society:

- Engenders a culture of learning throughout life.

- Aims to develop motivated, engaged learners who are prepared to conquer the unforeseen challenges of tomorrow as well as those of today.

- Takes learning to the learner, seeing learning as an activity, not a place.

- Believes that learning is for all, and that no one should be excluded.

- Recognises that people learn differently, and strives to meet those needs.

- Cultivates and embraces new learning providers, from the public, private, and non-governmental (NGO) sectors.

- Develops new relationships and new networks between learners, providers (new and old), funders, and innovators.

- Provides the universal infrastructure they need to succeed—still physical but increasingly virtual.

- Supports systems of continuous innovation and feedback to develop knowledge of what works in which circumstances (Cisco Systems, 2010, $\mathrm{v}-\mathrm{vi})$.

Does the summation of the characteristics of the learning society by a multinational IT company make it a North American or European idea, alien to the reality of sub-Saharan Africa or South Asia? As noted below, the learning needs and solutions of today's diverse, globalised world are, to a degree, common, a fact emphasised by a forward-looking technology pioneer and relevant to the developing world.

\section{$2.2 \quad$ Lifelong Learning - A Corollary of the Learning Society}

Lifelong learning offers a holistic perspective on the role of education in a person's life cycle. It affirms that learning, as a continuous process in life, plays an essential role in enabling individuals to adapt to, and deal with, new challenges and changes in their lives and surrounding environment. Lifelong learning, embracing all forms of educational and learning experiences, helps individuals to engage in purposeful interactions with their environment through the development of their knowledge, skills and critical thinking abilities. Implicit to the idea of lifelong learning is the concept of 'life wide' learning. While the former emphasises the continuity of learning throughout the human life cycle, the latter recognises that people find it necessary to engage in multiple learning activities simultaneously, through different modalities and in varying settings. Lifelong learning is intended to enable individuals to become active social agents-people who are able to act, 
reflect and respond appropriately to the cultural, social and development challenges they face both as individuals and as members of society (MedelAñonuevo et al. cited in Ahmed, 2009, 7). Life wide learning thus relates to the multiple and parallel roles of a person in society, as an added dimension of lifelong learning.

To sum up, in human life cycle in today's world, the traditional emphasis on building the foundation of basic knowledge and competencies and acquiring the intellectual and technical tools of learning in the first quarter of life has to be complemented by lifelong learning in a learning society where all participate in and contribute to learning throughout life.

Antecedents of Lifelong Learning Discourse and the Post-2015 Agenda

Despite a half-century of discussion and discourse aimed at innovation and progress, traditional paradigms and ways of thinking persist in education. The Education for All (EFA) movement, launched in 1990 at the World Conference on Education for All in Jomtien, Thailand and followed up by the EFA Dakar Framework for Action in 2000 with the adoption of six global education goals - which are in themselves a remarkable initiative of the international community - is a testimony of the endurance of conventional, narrow perceptions of education and learning. This limited view was again reflected in the education component of the 2000 Millennium Development Goals (MDGs) for global development, to be achieved by 2015. The same issues arise with new urgency as global development dialogue turns to the post-2015 development and education agenda.

The Jomtien Education for All conference in 1990, in fact, attempted to articulate a broad vision of education and learning. It visualised adult education as a key component of lifelong learning and argued that beyond universal and compulsory basic education, youth and adults are entitled to a wide range of opportunities as his or her own agent of learning and personal development. In specifying concrete goals and strategies and formulating programmes, however, this rhetoric was largely unfulfilled in practice (see Ahmed, 2009).

Ten years hence, in 2000, upon reviewing progress thus far, the Dakar Framework for Action attempted to redress a perceived imbalance in the Jomtien 'framework for action' in the relative neglect of elements of basic education other than primary education, such as early childhood education and development, literacy in a broader sense, and adult and continuing education. The Dakar Framework for EFA, however, did not specify quantitative goals or 
targets for early childhood development. As a result, progress in this area has been slow.

While some attention has been paid to preschool education, primarily in terms of school preparedness, there has been a relative neglect of the care and development needs of young children in the critical early years of life. The Dakar Framework set two goals related to adult learning and education-one in the area of adult literacy (Goal 4) and the other in life skills and lifelong learning (Goal 3). It also indicated targets for literacy and outlined the kind of actions that might be pursued by countries to achieve this goal, but, interestingly, failed to do likewise for 'life skills and lifelong learning.'

The commentary on Goal 3, related to lifelong learning, held that 'All young people must be given the opportunity to gain the knowledge and develop the values, attitudes and skills that will enable them to develop their capacities to work, to participate fully in their society, to take control of their own lives and to continue learning' (UNESCO, 2000, 12). In the commentary on literacy (Goal 4), the Dakar Framework document appropriately noted that there were some 880 million people who could not read or write, two thirds of them women, and 'yet, the education of adults remains isolated, often at the periphery of national education systems and budgets' (UNESCO, 2000, 13).

A close reading of the two EFA Goals and their elaboration suggests an attempt to differentiate between the ends to be achieved by the two goalsin terms of relevant content, objectives and potential learners-leading to an untenable dichotomy. The life-skills and lifelong learning goal was not quantified, and strategies for its achievement were not articulated. It referred simply to learning content and objectives; essentially, in a process of continual learning, the learners should be able to acquire values, attitudes and skills that would serve them throughout life. Unlike primary education and adult literacy, concrete programme strategies, actions or targets for lifelong learning were not mentioned. The adult literacy goal, in contrast, emphasised the mechanics of literacy skills and the importance of equipping learners with literacy as a tool with which learners might continue their education. This somewhat narrow and restrictive view of literacy skills, and its separation from life-skills and lifelong learning, represents a lost opportunity to place literacy and adult education firmly within a common framework that would be meaningful and relevant to each learner (Ahmed, 2009).

The Education for All initiative proclaimed in Jomtien in 1990 and the subsequent Dakar Framework of 2000 influenced policy-making and programme strategies in developing countries. Some Asian nations that have long-established non-formal and continuing education programmes have been able to overcome, to a degree, the apparent disjunction implied in Dakar between 
the mechanical acquisition of literacy and learning content and objectives. The conceptual and definition incoherence of adult and lifelong learning in many countries around the globe reflects, in part, the influence of what may be called the 'Dakar dichotomy' between adult literacy on the one hand, and the skills and learning needs of youth and adults on the other (Ahmed, 2009). The tension inherent to understanding this limited conceptualisation of literacy as a component of lifelong learning is more evident in countries where adult illiteracy remains a serious problem than in those where major progress has been made in expanding basic education opportunities. These latter states have had significantly more experience in developing the wide array of literacy, non-formal and continuing education activities that are the building blocks of lifelong learning (Ahmed, 2009, 16-17). It is a classic paradox of national development that those countries most in need of adult learning and education to fulfil their developmental aspirations are those least capable of providing such opportunities. This pattern is a persistent and formidable challenge for the post-2015 development agenda.

\section{The Relevance of Lifelong Learning / Learning Society to the Post-MDG Debate}

The experience and progress (or lack thereof) achieved thus far, informed by the restrictive view of education in MDG 2015 and its limited scope in EFA, underscore the need for a (re)conceptualisation of development as human capability enhancement, emphasising individual agency, empowerment, and the ability to make and exercise choices. Such a conceptualisation is essential to the promotion of human rights, human dignity and just societies. The discourse on the post-2015 development agenda, both domestically and globally, is an opportunity for civil society and other education and development stakeholders to articulate a human capability approach to development, installing it as the measure and criterion for selecting goals and indicators of development, and the basis for adapting and adjusting global goals to national contexts (see Ahmed, 2013). The question thus arises as to how, precisely, an overarching vision for development - the 'world we want' - can place human capability enhancement at the centre. Can the human capability, understood as the empowerment and agency of people, for achieving human rights and dignity for all be the touchstone and rationale for post-MDG sectoral/thematic goals in poverty reduction, sustainability, public and individual health promotion, lifelong learning and skills training, good livelihoods and generally meaningful, productive and rewarding lives? 
Such an overarching vision, the proponents of the human capability approach (as advocated by Amartya Sen and others) argue, does not undermine the sectoral/thematic goals listed above. Rather, it offers a means of justifying their pursuit and prioritisation in diverse regional and national contexts. An overarching vision of human capability and agency, human rights and human dignity places education and learning, the key mechanism for enhancing human capability, at the centre of development agenda, rather than the sectorally differentiated margins. Capabilities are not to be equated with a narrow definition of outcomes, qualities or competencies related to educational programmes, though these deserve due attention in designing and implementing learning activities. In Sen's view, capability is both a goal and an indicator of development (Walker and Unterhalter, 2010). The enhancement of human capability as a dimension of development thus differs from the orthodox economic notion of human capital as the driver of development, wherein the human being is a mere tool of economic production. ${ }^{2}$

Sen has generated debate by asking why India has lagged behind China in economic development and poverty reduction. According to Sen and his coauthor Dreze:

China made enormous progress (especially in comparison with India) very early towards universal access to elementary education, health care and social security - much before embarking on market-oriented economic reforms in 1979. [...] China's growth oriented policies during that period benefited a great deal from the solid foundations of human development that had been laid earlier, but also retained that commitment in many ways. (Dreze and Sen, 2013, 67)

Sen argued the case for the human capability approach by invoking the Asian historical experience:

$[\mathrm{M}]$ any Indian policy analysts may have missed that human capability is not only important in itself, but that human capability expansion is also a kind of classic Asian way of having sustained economic growth. It started in Japan, just after the Meiji restoration, where the Japanese said: 'We Japanese are no different from the Europeans or the Americans; the only reason we're behind is that they are educated and we are not'. They then had this dramatic expansion in universal education and then, later,

2 See also Chapter 7 in this volume regarding the significance of the capability approach in the context of skills development in South Africa. 
widespread enhancement of healthcare. They found that a healthy, educated population served the purpose of economic growth very well. That lesson was later picked up in South Korea. Korea had quite a low educational base at the end of the Second World War. But following Japan, they went in the same direction. The same happened in Singapore, Hong Kong, Taiwan and, to some extent, even Thailand. And gradually, in a smaller way, in Indonesia. Of course, they reaped as they had sown. So human capability expansion is very important for Asian economic growth. (Interview with Sen, Derbyshire, 2013)

The pivotal role of lifelong learning within the vision of human capability expansion makes building the learning society a goal of paramount importance. Industrial and post-industrial societies - members of the Organisation for Economic Co-operation and Development (OECD), for instance-have already acquired the paraphernalia of lifelong learning and the learning society. Their progress in this regard is evident in the widespread opportunities provided for the continuation of youth and adult education outside formal institutions (Hasan, 2012). In these states, the pursuit of lifelong learning may not, therefore, have the same level of priority as it does in developing countries, though the effort to broaden and deepen the concept and attendant practices should continue in wealthier states as well.

The concern thus arises as to whether adult and lifelong learning is being neglected in the post-2015 global development discourse and accorded only secondary priority in the formulation of the post-2015 EFA agenda. The work of the Centre for Universal Education, based in the Brookings Institution, an influential American think-tank, for instance, relating to the definition of learning objectives and measurement of progress in achieving them, heightens the concern. The Centre for Universal Education learning metrics project largely restricts itself to the examination of formal compulsory education from preschool to the lower secondary level. Yet, surely, it cannot be presumed that education and learning are completed by age 15 . And what of early childhood development, covering the years between birth and institutional preschool, at age 5 or so? There is now overwhelming scientific evidence relating to early brain development and the importance of social-intellectual stimulation in the first thousand days of life, casting new light on the critical role of parents and early childhood care-givers. It is thus essential that they be supported through parenting and adult education - especially in disadvantaged segments of society (CUE, 2013a and 2013b).

It is worth recalling that EFA was launched in 1990 with the ambition of meeting basic learning needs, including adult literacy and education in a framework 
of lifelong learning. The fact that EFA and the MDGs have failed to do justice to this broad vision of education cannot be a justification for merely staying the wrong course in the post-2015 era (Ahmed, 2013, 45-47). Clearly, the challenge for developing countries will be to transform their educational systems and institutions into elements of the learning society, unconfined by time, space, delivery mechanisms and credentials imposed by the institutions and structures of conventional formal education. The modern explosion of human knowledge, revolution in information and communications technology, and rapid pace of change in the globalised world have converged to render the learning society and lifelong learning not only essential, but also eminently achievable.

\section{$5 \quad$ Overview of Lifelong Learning in Bangladesh and Asia}

A review of the state of adult and lifelong learning in the Asia Pacific region undertaken in preparation for the 6th Global Conference on Adult Education in Belem, Brazil in December 2009 provides an overview of concepts, strategies and programmes currently employed in the region. Conference reports and studies produced by the UNESCO Regional Office in Bangkok, an early and ardent promoter of the community learning centre (also known as CLC) as the vehicle for adult and lifelong learning, add to the understanding of the overall picture.

Such information is particularly important as many governments of developing countries in Asia Pacific do not have the specific policies, programmes or resources to place non-formal and adult education programmes within a lifelong learning framework. One way of making sense of the diversity in lifelong learning (also known as LLL) and adult education policies, programmes and strategies is to categorise countries according to the common features among them. Based on empirical assessment of the various states' progress in adult and lifelong learning, the afore-mentioned regional review developed a five-part taxonomy of the regional, consisting of: a) low basic education states; b) Asian giants (China and India); c) advanced basic education countries; d) developed Asia; and e) 'foreshadowing the future', illustrated by the Republic of Korea (Ahmed, 2009). This is clearly not a rigorous, mutually-exclusive classification, but does represent a convenient heuristic for generating a broad understanding of the diverse situations and contexts of adult education and lifelong learning in the region. Within this typology, Bangladesh and other South Asian countries, with the exception of Sri Lanka, fall under the category of low basic education, a key feature of which is weak and relatively ineffective adult and lifelong learning provisions. Most East Asian and South-East Asian 
countries, including Indonesia, Malaysia, Thailand and Vietnam, come under the advanced basic education group. Due to their size, China and India are categorised separately, but India could also be considered a low basic education country and China an advanced basic education country.

\subsection{Bangladesh: Lifelong Learning and the Potential of Community Learning Centres}

In 2006, the Government of Bangladesh adopted a forward-looking nonformal education (also known as NFE) Policy Framework. The principal features of the policy are listed below.

- The framework's mission is to provide lifelong learning opportunities to improve the quality of life of children, youth and adults, including those with special needs, who have missed out on formal education. An early priority is the reduction of illiteracy by at least 50 per cent by 2015 .

- It emphasises alternate learning opportunities through non-formal channels for the basic education of children unable to participate in formal primary schools, second-chance learning opportunities for adolescents and adults, and a 'menu' of need-based continuing education.

- The framework aims to build a 'culture of quality' in all non-formal education programmes. Third party involvement in the assessment of effectiveness is seen as a means of quality improvement.

- It promotes non-formal channels for vocational, entrepreneurial and employment-related skills and seeks to establish equivalency between formal and non-formal qualifications.

- It proposes moving to a decentralised non-formal education operation system, with coordination and linkages among governmental organisations, non-governmental organisations (NGO), community-based organisations, the private sector and civil society.

- The framework encourages community ownership as a means of ensuring the sustainability of non-formal education programmes (Ahmed, 2009).

At present, the central Bureau of Non-Formal Education (BNFE) manages a number of post-literacy and continuing education projects. Building the organisational structure and mechanisms required to implement the policy framework with the involvement of major stakeholders, such as non-government development organisations, community organisations and research and academic institutions, is recognised as the primary challenge for the future.

A recent study of mapping the extent of existing non-formal education, however, indicates that the coverage of on-going projects is generally very low 
and inequitably distributed amongst the potential target population. With respect to programme delivery, the teaching-learning process, the development of curriculum and materials, and the ability of learners and providers to exercise choice were very limited. The technical capacity in non-formal education, especially in the public sector, is inadequate to the extent that 'it would be an uphill task to launch the programmes ideally required unless a massive professional skill development programme is planned' (Bangladesh Country Report cited in Ahmed, 2009). A comprehensive non-formal education sub-sector plan considered necessary was to be developed in line with the non-formal education Policy. As of 2013, this comprehensive plan has yet to be written. The absence of an overall strategy to give effect to this progressive policy statement is reflected in the fragmented efforts, ineffective outreach, and lack of coordination between the government and active NGO sector. As a result, the problems of quality, efficiency and sustainability, all of which would benefit from increased cooperation, go unaddressed.

The state of community learning centres is a case in point. The Bureau of Non-Formal Education claims to be operating some 7,000 community learning centres under the auspices of its donor-supported post-literacy and continuing education project (in the context of a population of 160 million and 60,000 villages, this number is not necessarily particularly high). These centres offer a curriculum combining a consolidation of literacy and income-earning skills identified as locally relevant. The teachers are appointed by the Bureau of Non-Formal Education and centres are managed in conjunction with a local committee. In addition to the deficiencies in quality assurance, efficiency and accountability, the centres are also constrained by total dependence on donor funds, which may run out in 2015. A sustainability strategy incorporating resources from community, NGOs, local government and regular government budgets has not been developed.

A number of NGOs have been engaged in running community learning centres, under various labels, for over a decade. About 5,000 such centres are estimated to be in existence, with the preponderance run by a half dozen NGOs, including the Bangladesh Rural Advancement Committee (BRAC), Dhaka Ahsania Mission, Friends in Village Development Bangladesh (FIVDB) and Rangpur-Dinajpur Rural Services (RDRS). Such centres also rely on donor funding, but the NGOs have worked with communities to establish firm local embeddedness and mobilise support, with an eye to sustainability. The fact that many of these centres have been in operation for ten or more years testify to both their prospects for sustainability as well as their relevance and responsiveness to community needs. Multi-purpose Community Learning Centres, or Gonokendros, were established in the mid-1990s as community reading rooms 
as part of the continuing education programmes of BRAC and other NGOs. Centres established by BRAC are registered as trusts and have become mostly self-financing, as users pay a small membership fee and funds raised by the community are matched by a capital grant from BRAC. These centres are open to adults, children and students and, in addition to their literacy promotion activities, provide IT and vocational training (in electronics, livestock rearing, horticulture, fish culture, poultry, etc.) in collaboration with the Department of Youth Development and other government agencies (BRAC, 2012).

Clearly, Bangladesh does not yet provide a good example or a workable model of the community learning centre as a vehicle for effective lifelong learning. But does this necessarily imply that such an option is unworkable and should not be considered? One could imagine, for instance, an agreement between the Bureau of Non-Formal Education and the successful literacy NGOs to jointly operate the 7,000 donor-supported centres and use the funds and technical capacities to develop a community-based sustainability model, supported by the government, NGOs and the private sector, as well as the various communities and local government. As it currently stands, without a strategic plan for government support to community learning centres, NGOs are struggling to keep the centres open. Potential donors justifiably raise questions about the future of the centres in the absence of a demonstrable national commitment. At the same time, Bangladesh could use several times the current number of community learning centres to bring the more than 60,000 villages within the reach of a functioning centre.

With a network of NGO-run community learning centres already in operation, and following the major expansion of primary and secondary education in recent decades, the basic building blocks for lifelong learning already exist. The forum of education NGOs established by the Campaign for Popular Education (CAMPE) provides a strong and lively platform for debate and dialogue amongst education stakeholders, including the government. The efficiency and efficacy of service delivery may be, and must be, enhanced by leveraging advances in information technology. Similarly, the renewal and enrichment of learning content must be responsive to learners' needs and demands. With this in mind, the mode and modalities of feasible partnership(s) between the government and civil society must be critically examined.

The multi-sectoral Bangladeshi civil society body, known as the People's Forum for MDG (PFM), established in 2005, has taken it upon itself to engage with the discourse of the new Global Agenda and make the case for human capability enhancement. In doing so, it has proposed a total of 12 development goals, two of which relate to education and human capacity development, as shown in Table 6.1. 
TABLE 6.1 Proposed education goals, targets and indicators for the post-2015 Development Agenda, as put forward by the Bangladesh People's Forum for MDG

\begin{tabular}{|c|c|c|}
\hline Goal & Targets & ndicators \\
\hline $\begin{array}{l}\text { 4. All children up } \\
\text { to the age of } \\
\text { prohibition of } \\
\text { child labour } \\
\text { (age 14) will } \\
\text { complete } \\
\text { compulsory } \\
\text { education of } \\
\text { acceptable quality }\end{array}$ & $\begin{array}{l}\text { 4.1. All children from } \\
\text { birth to transition into } \\
\text { primary school } \\
\text { participate in } \\
\text { organised ECD } \\
\text { programmes, including } \\
\text { preschool; } \\
\text { 4.2. Ensuring } \\
\text { acceptable educational } \\
\text { quality with adequate } \\
\text { provisions for primary } \\
\text { and post-primary } \\
\text { education, including } \\
\text { teaching personnel; }\end{array}$ & $\begin{array}{l}\text { 4a. Proportion of children with birth } \\
\text { registration, broken down by urban- } \\
\text { rural locale and gender; } \\
\text { 4b. Proportion of parents/care givers } \\
\text { of young children from birth to } 8 \text { years } \\
\text { participating in organised parenting } \\
\text { skills and knowledge programmes, } \\
\text { with income quintile and urban-rural } \\
\text { breakdown; } \\
\text { 4c. Proportion of children } 3-5 \text { years } \\
\text { participating in ECD programmes, } \\
\text { with income quintile and urban-rural } \\
\text { breakdown; }\end{array}$ \\
\hline
\end{tabular}
4.3. Completion of 4d. Proportion of children 5-6 years primary and post- participating in preschool primary education by programmes, with income quintile and all eligible children; $\quad$ urban-rural breakdown;
4.4. Major expansion of secondary education.

4e. Proportion of primary and secondary schools meeting essential quality standards for physical facilities, learning equipment and environment, and teaching personnel standards;

4f. Proportions of students entering and completing primary school at designated age, with gender and urban-rural breakdown;

4g. Gross and net enrolment in primary and secondary education; 


Goal Targets Indicators

\begin{tabular}{|c|c|}
\hline 5. All youth and & 5.1. Universal \\
\hline & \\
\hline articipate in & cemtres, spaces, \\
\hline articipate in & programmes, and \\
\hline lifelong learning & learning technology \\
\hline lated to & networks; \\
\hline relihood, work, & \\
\hline tizenship and & 5.2. 80 per cent of \\
\hline ersonal & youth and adults \\
\hline Ifilment & participate in lifelong \\
\hline & learning; \\
\hline
\end{tabular}

5.3. Assessed basic literacy competency achieved by all youth and adults, with self-sustaining functional competency achieved by 80 per cent of youth and adults. 4h. Assessed achievement of students against competency standards in languages ( first language and English), mathematics, and science at primary and secondary levels, with gender and urban-rural breakdown.

5a. Proportion of youth and adults making regular use of learning centres, spaces, programmes, and learning technology networks, with gender, income quintile and urban-urban/ slum-rural breakdown;

5b. Proportion of youth and adults participating in literacy and postliteracy, work, and livelihood skills training and personal fulfilment in community learning centres and other education programmes. with gender, age and urban-urban/slum-rural breakdown;

5c. Assessed competency achievement of youth and adults in literacy at basic and functional or self-sustaining levels.

Source: PFM (2013) 'A New Global Partnership: For Sustainable Human Development through Eradicating Poverty and Transforming Economies', Draft post-2015 Development Agenda based on a synthesis of position papers prepared for Bangladesh People's Forum for MDG (PFM), 8 July, cited in Ahmed, 2013, 47-48.

The PFM proposal highlights the fact that along with strengthening basic and post-basic education in both the formal and non-formal sectors, the structures and content of lifelong learning must be created and enhanced in Bangladesh. 
China's progress in massively expanding lifelong learning opportunities and creating 'learning cities and communities' since the 1990s may serve as a reference point for the issues, challenges, and potential currently facing Bangladesh. Although the circumstances and contexts differ, lessons derived from the Chinese experience, while not necessarily transferrable directly, may point up issues and concerns that are crucial to lifelong learning's success.

\subsection{China: From Literacy Towards Lifelong Learning}

China, which viewed universal literacy as key to its revolutionary struggle for social and political change even before its liberation in 1949, has since advanced further, broadening the literacy effort into a lifelong system of adult and continuing education. It must be acknowledged, of course, that China does not often use the label 'community learning centre' to refer to the diverse and widespread national continuing learning opportunities and its experience is not directly comparable to the fledgling adult and non-formal education activities in Bangladesh. The point, however, is that an institutional, community-level base, whatever the name, is necessary for the furtherance of lifelong learning.

Similarly, support mechanisms for determining educational content and methodology as well as mobilising human and financial resources must also be in place. Such efforts must be guided by a theory of nation-building that places education at the centre. This is where the Chinese experience becomes pertinent, not as a model to be transplanted, but as a diagnostic tool for identifying potential problems and solutions in developing a learning system.

Literacy as the vehicle for nation-building and economic development has been a dominant theme in Chinese revolution and reform throughout the twentieth century. The communist movement led a nationwide struggle to overcome mass illiteracy. As observed by Peterson: 'Indeed, the literacy programs mounted in China after 1949 constitute what is perhaps the single greatest educational effort in human history' (Peterson, 1997, 3). When confronted with the twin challenges of ensuring prosperity for its people and becoming a global leader, China recognised the necessity of broadening the scope and mandate of adult learning to make it an instrument of lifelong learning. By one estimate, the potential scope of lifelong learning in China is at least three times that of formal schooling: there are a billion candidates for lifelong learning, composed of 790 million workers who need to renew their knowledge and skills; 120 million rural-urban migrants who need to adapt to new work and living environments; and 144 million elderly who want to be active citizens and pursue a meaningful and enriched life of leisure (Hao cited in UIL, 2010, 3). 
A major expansion of opportunities in China has occurred to enable rural people with no formal education beyond primary school to acquire relevant knowledge and skills. Continuing education is offered at adult secondary vocational schools and adult higher education institutes, which grant diplomas. There are also provisions for non-diploma continuing education, such as secondary vocational schools for farmers, which have provided training to over 1.1 billion people since the mid-1980s. Workplace training, moreover, is offered to around 90 million participants every year. Continuing education opportunities are also provided to administrative cadres and other professionals in government, industries and non-governmental organisations, and are often aimed at women, youth and workers (UIL, 2010).

Additionally, China has constructed a distance education and service platform utilising satellite, television networks and the Internet. The number of registered distance learning students in regular higher education institutions recently reached 1.1 million(UIL, 2010). A national learning communities pilot project has been initiated in 114 locations, offering various forms of continuing education coordinated effectively to ensure a consistently high quality of service.

Provincial governments also have set up over 400 provincial learning communities (UIL, 2010). The city of Shanghai alone, for example, has more than 6,000 learning stations as well as other basic and tertiary level distance, faceto-face and combined educational facilities outside the formal education and training system. Shanghai is thus a striking example of the emerging architecture of lifelong learning. These are the building blocks for the 'learning city' that Shanghai has pledged to become and will, in time, form the basis of a learning society (Li cited in UIL, 2010, 5).

Key 'enabling measures' for the development and promotion of lifelong learning either currently underway or identified as necessary are:

- An overall legislative framework for lifelong learning, which will clarify the rights and responsibilities of the government, civil society organisations and individuals;

- A national lifelong learning support and service system that covers both urban and rural areas through the use of information and communication technology, including satellite, broadcast networks and the Internet;

- Improved learning outcomes assessment and accreditation, and credit transfer systems;

- Research into ways of developing personal accumulation of lifelong learning credit and integrating this, step by step, into the continuing education system; 
- A national qualifications system in which knowledge, skills and competencies are equally weighted, and diploma and professional qualifications are mutually transferable;

- A learning budget assurance and cost-sharing system which clarifies the responsibilities of the government, employers and individuals, thereby ensuring that more support is given to disadvantaged and vulnerable groups; and

- Research into mechanisms to incentivise increased spending on workplace learning by industries, organisations and civil departments (Hao cited in UIL, 2010, 5).

The contrast between China and Bangladesh could not be greater. China's diverse and vast adult and continuing education efforts are seen as elements of a comprehensive national lifelong learning system backed by strong political, legal and resource support. Particularly remarkable in this system are what are referred to as 'enabling measures' underway or identified, including the overall legislative framework, an information and communication technology-based national support and services system; learning outcomes assessment and accreditation, and credit transfer systems; various steps to enhance resources for lifelong learning, and the creation of learning communities and learning cities. These elements, are essential to building a network of community learning centres as an effective institutional tool for lifelong learning.

What Can Be Done?

A complex mosaic of needs, constraints, actions and possibilities exist in Bangladesh and its South Asia neighbours. Within this rich mosaic lie the elements of a strategy for action capable of guiding the future development of lifelong learning, with the community learning centre serving as a major vehicle.

Since the UNESCO regional office in Bangkok first promoted community learning centres in the 1990s, they have spread to more than two dozen countries in the region. As illustrated by the range of activities and initiatives present in China, the nomenclature used to refer to community learning centres varies by national context, as does the scope and emphasis of the services. Correspondingly, it has been relatively difficult to count and compare the numbers in various countries. A 2009 report indicates the existence of 28,500 community learning centres in 16 developing countries in the Asia Pacific region, but notes that data from Bangladesh, China, India, and Sri Lanka were 
not available and several states, despite general knowledge of their more expansive offerings, reported relatively small numbers (Oyasu and Riewpituk, 2013). There is no doubt that the actual number of institutions resembling community learning centres is several times larger than the estimate given above. There is also no doubt that reaching and serving the over 60,000 villages in Bangladesh, or 600,000 in India, for example, will require many times more than whatever number of community learning centres exists at present. Bangladesh has some 80,000 primary schools; what would be a valid argument for not having a comparable number of community learning centres?

Of course, it is not just a numbers game. The centres must clearly define goals and learning objectives, identify the people to be served, and have the wherewithal to provide relevant services of acceptable quality.

As indicated above, the debate and discussion regarding the concepts and practices of lifelong learning and community learning centres as a potential institutional base has continued. Leading up to the CONFINTEA VI in 2009, this discourse was summarised in the Asia Pacific synthesis of progress in Asia. Subsequently, the outcome of CONFINTEA VI was expressed in the Belem Framework for Action, and the follow-up Second Global Report on Adult Learning and Education (GRALE 2) on progress since 2009 was recently released. Various conference reports and studies conducted under the auspices of UNESCO Bangkok Regional Office and UNESCO Institute of Lifelong Learning (UIL) have also been added to this body of work. ${ }^{3}$ Together, they provide a strong basis for proposing principles and strategies regarding what might be done in Bangladesh and neighbouring states to promote lifelong learning and strengthen and expand community learning centre as its vehicle (see Ahmed, 2009; UIL, 2009 and 2013; UNESCO, 2011 and 2012).

The emerging principles and strategies derived from the recent review and analysis of the Asia Pacific region can be grouped under the headings of policy development and commitment, institutional and governance concerns, ensuring quality with equity, learning and content relevancy, and resource adequacy.

\subsection{Commitment to Lifelong Learning and the Creation of Learning Societies and Communities as a Policy Imperative}

The task at hand requires the creation and implementation of an overarching vision of diverse and widespread youth and adult learning as the core of the lifelong learning approach, leading to a rich network of opportunities throughout life informed by learners' needs and aspirations. A wide spectrum

3 The UIL was established as the UNESCO Institute of Education in 1952 in Hamburg. It was renamed the UNESCO Institute of Lifelong Learning in 2006. 
of learning objectives and groups of learners are to be served by formal, nonformal and continuing education programmes and an enriched informal learning environment, all of which are components of lifelong learning. The logical corollary to the idea of lifelong learning is that as all citizens benefit from, and contribute to, learning and society, they create a learning environment and communities become learning-friendly. The community learning centre, as a general concept, may act as the institutional base for this learning network. The content of programmes and learning objectives, of course, must be relevant and meaningful to learners, and address the critical concerns of society.

\subsection{Governance and Legal Framework}

Related to policy development is the formulation of the legal framework required to give effect to the policy. The legal provisions and associated rules, regulations and procedures derived from the adopted laws must help develop a systemic approach to lifelong learning and strengthen the governance and management of lifelong learning activities. China and several East and South Asian countries have either put in place or are in the process of refining a comprehensive legal framework.

If supported by such a legal framework, the network of community learning centres could become the vehicle for creating lifelong learning opportunities. These are most effective when they directly disseminate knowledge, provide relevant training and connect learners with ancillary support. community learning centres, brought together into national or regional networks for technical support, have the potential to act as a conduit for the education and learning opportunities necessary to reduce poverty and improve overall quality of life. Building effective partnerships among the concerned government agencies, non-governmental organisations, communities, and academic and research institutions is equally important to leveraging community learning centres to serve these goals. The legal and policy framework, therefore, has to support and promote this partnership-building. Only then can community learning centres be the essential building blocks for lifelong learning in the learning society.

\subsection{Relevance of Learning Content}

The objectives and content of lifelong learning must be relevant to the critical concerns of society. The raison d'être of lifelong learning is its links and direct relevance to both the identified needs and problems of individual learners and the collective priorities of society. This theoretical position, however, is not automatically translated into practice unless it is systemically integrated into the conceptualisation and design of strategies and programmes. The urgent task of establishing the relevance of lifelong learning to the goal of enhancing 
people's capabilities, knowledge, understanding and skills for sustainable development is a case in point. One of the key messages of CONFINTEA VI was that the planet will not survive unless it becomes a learning planet (Walters cited in UIL, 2010, 11).

To be effective, poverty reduction programmes must link literacy skills, employment skills, quality of life components and ancillary support. It is only in conjunction with ancillary support and other necessary factors, such as access to credit, management advice, market information and links with potential employers that skills training may result in an improved earning ability. Moreover, poverty is not just a matter of income. Fighting poverty through adult learning also, for instance, entails improvements in health and nutrition, protection from disease, and the knowledge and practice of family planning. Correspondingly, to be relevant and successful, high on the list of learning priorities must be issues such as parents' and care-givers' role and skills in early development of children, the status of women in the family and community, women's participation in economic activities outside the home, and the dissemination of information and knowledge relating to government services and people's entitlement to access them. These are often the priorities of individual learners and communities (Ahmed, 2009).

\subsection{Ensuring Quality with Equity}

An equivalency framework for assessing learning and competencies has to be established. A national qualifications framework helps deal with issues of access, mobility, quality and programme development in lifelong learning activities in an integrated way. In situations where credentials and certifications are important, the establishment of equivalency among them is obviously crucial. Equivalency may also serve as a measure of quality enhancement measure for all kinds of programmes (Walters cited in UIL, 2010, 10). Of course, this mechanism can only function effectively when adequate arrangements for coordination, communication and cooperation amongst key stakeholders are in place. Contestation and debate is to be expected, but if stakeholders share a vision of core objectives, and rely upon research-based evidence, these can be resolved (see UIL, 2013, chapter 6). In Bangladesh, the National Skill Development Council and Bureau of Non-Formal Education are currently at work developing a qualifications framework to guide the establishment of equivalency amongst competencies acquired in different ways.

Advances in information and communication technologies have opened new frontiers in creative content delivery and reaching and serving new groups of learners. The potential, however, is far from realised. In adult and lifelong learning, given their broad scope and mandate, information and communica- 
tion technologies can help bridge the prevailing digital divide by severing the 'insidious link between quality and exclusivity' in education and promoting wider access, higher quality and lower costs, 'all at the same time' (Daniel cited in UIL, 2010,11).

\subsection{The Imperative of Significantly Increasing Public Resources}

The adult learning components of lifelong learning make up less than a fraction of one per cent of the government education budget in developing countries, and a microscopic share of Gross Domestic Product (GDP). With an expected increase in total government education spending in most countries in the coming years, it is reasonable to aim to raise the share of adult and non-formal learning components of lifelong learning to three to five per cent of the education budget in the medium term, and even higher in the longer term. Such an increase would certainly be consistent with the proclaimed role of adult learning and non-formal education as essential components of lifelong learning. As such, a strategy to ensure balanced support for different components of lifelong learning, including formal education, should be developed. A vigorous effort to raise greater financial resources from diverse sources-including the private sector, communities and external assistance-is also essential (see UIL, 2013, chapter 4).

To conclude, a wide spectrum of learning objectives and learners must be served by formal, non-formal and continuing education programmes within an enriched informal learning environment, all of which are components of lifelong learning. The logical corollary to the idea of lifelong learning is that as all citizens benefit from, and contribute to, learning; societies are empowered; and communities become learning friendly. As argued in this chapter, based on an assessment of the available empirical evidence, an institutional mechanism for making the provisions required for diverse and multifaceted learning is indispensable. The community learning centres, if they did not exist, would have to be invented, to make the grand vision of lifelong learning in the learning society a reality.

\section{References}

Ahmed, M. (2013) The Post-2015 MDG and EFA Agenda and the National Discourse about Goals and Targets - A Case Study of Bangladesh (Geneva: Graduate Institute of International and Development Studies).

- (2009) The State and Development of Adult Learning and Education in Asia and the Pacific Regional Synthesis Report (Hamburg: UIL). 
BRAC (Bangladesh Rural Advancement Committee) (2012) Multi-purpose Community Learning Centres (Gonokendros), http://education.brac.net/multi-purpose-commu nity-learning-centres (accessed on 10 March 2014).

CUE (Centre for Universal Education at Brookings) (2013a) Toward Universal Learning: What Every Child Should Learn, LMTF Report, No. 1, http://www.brookings.edu/ research/reports/2013/02/learning-metrics (accessed on 10 March 2014).

(2013b), Toward Universal Learning: A Global Framework for Measuring, LMTF

Report, No. 2, http://www.brookings.edu/research/reports/2013/07/global-frame work-measuring-learning (accessed on 10 March 2014).

Cisco Systems (2010) The Learning Society (San Jose, CA: The Cisco Systems Inc.), http://www.cisco.com/web/about/citizenship/socio-economic/docs/Learning Society_WhitePaper.pdf (accessed on 10 March 2014).

Coombs, P. and M. Ahmed (1974) Attacking Rural Poverty: How Non-formal Education Can Help (Baltimore: Johns Hopkins University Press).

Delors, J. (Chair) (1996) Learning: The Treasure Within, Report to UNESCO of the International Commission on Education for the Twenty-first Century (Highlights) (Paris: UNESCO), http://unesdoc.unesco.org/images/0010/001095/109590eo.pdf (accessed on 1 April 2014).

Derbyshire, J. (2013) 'Prospect Interviews with Amartya Sen', Prospect Magazine, 18 July 2013, https://www.prospectmagazine.co.uk/magazine/prospect-interviews-amartyasen-the-full-transcript-jonathan-derbyshire/\#.Ux8INryWRz8 (accessed on 11 March 2014).

Dreze, J. and A. Sen (2013) An Uncertain Glory —India and Its Contradictions (London: Allen Lane).

Faure, E. et al. (1972) Learning to Be: The World of Education Today and Tomorrow. Report of the Edgar Faure Commission (Paris: UNESCO).

Hasan, A. (2012) 'Lifelong Learning in OECD and Developing Countries: An Interpretation and Assessment' in Aspin, D.N. (ed.) Second Springer International Handbook of Education (Portland, OR: Powell Books), vol. 26, chapter 29, pp. 471-497.

Husén, T. (1986) The Learning Society Revisited (Oxford: Pergamon).

Hutchins, R.M. (1970) The Learning Society (Harmondsworth: Penguin).

Oyasu, K. and D. Riewpituk (2013) 'CLCs in the Asia Pacific Region', in Okayama ESD

Promotion Commission, Education for Sustainable Development and Kminkan/ Community Learning Centre (Okayama: Okayama University Press).

Peterson, G. (1997) The Power of Words: Literacy and Revolution in South China, 1949-95 (Vancouver: University of British Columbia Press).

UIL (UNESCO Institute for Lifelong Learning) (2013) Second Global Report on Adult Learning and Education —Rethinking Literacy (Hamburg: UIL). 
UIL (2010) Shanghai International Forum on Lifelong Learning: Summary Report of General Rapporteur, Shanghai, 19-21 May (Hamburg: UIL), http://uil.unesco.org/ fileadmin/keydocuments/LifelongLearning/en/Summary\%20of\%20General\%20 Rapporteur.pdf (accessed on 17 April 2014).

- (2009) The Belém Framework for Action, Sixth International Conference on Adult Education (CONFINTEA VI), Belem, Brazil, 1-4 December (Hamburg: UIL).

UNESCO (2012) Community Learning Centres: Asia Pacific Regional Conference Report (Bangkok: UNESCO Regional Office).

(2011) 'Sustainability of Community Learning Centres: Community Ownership and Support', Asia-Pacific Regional Action Research Studies (Bangkok: UNESCO Regional Office).

— (2000) 'Expanded Commentary' in Dakar Framework for Action (Paris: UNESCO).

Walker, M. and E. Unterhalter (2010) Amartya Sen's Capability Approach and Social Justice in Education (New York and Basingstoke: Palgrave Macmillan). 